\title{
The Power to Activate a Creative Core in Enterprise
}

\author{
Hiroyasu Yuhashi \\ Mobile Society Research Institute \\ NTT DOCOMO, INC. \\ Sanno Park Tower 2-11-1 Nagata-cho Chiyoda-ku Tokyo, Japan \\ yuuhashi@nttdocomo.co.jp \\ Junichi lijima \\ Graduate School of Decision Science and Technology \\ Tokyo Institute of Technology \\ Ookayama 2-12-1-W9-66 Meguro-ku Tokyo, Japan \\ iima.j.aa@m.titech.ac.jp
}

\begin{abstract}
A wide range of products and services has been commoditized as a result of globalization, and a lot of companies have been progressively working to draw on the knowledge creation of their employees to be more competitive. In this respect, some would argue that a "Creative Class" of employees determines the business results of a company. Social networking among employees is a platform for creativity, so when management supports such social networks, the strength of the organization increases. In this paper, we present a quantitative association from our previous research and a theoretical contemplation to provide a management method between the communication of employees and organizational collaboration. Further, we take the case of a company, which is an ICT (Information and Communication Technology) system integrator, using an RFID system, and confirm whether there are causal relationships through a multiple regression analysis of Bayesian statistics. As a result, we found that the egocentric collaboration networks of the Creative Core grew by activating communications (sending emails) among employees. Further, we propose some implications that allow control of collaboration within a company by encouraging communication of the "Creative Core," that is, the central members of the Creative Class by considering the results of this and previous research.
\end{abstract}

Keywords: Creative Core, Knowledge work, Communication, Collaboration, Social network, RFID system. 


\section{Introduction}

As the globalization of the economy progresses, a wide range of products and services has become commoditized. In the industrial world, measures such as downsizing and restructuring are gradually losing their effectiveness in maintaining sustainable competitiveness within markets. Drucker foresaw some big social changes in the next era. He commented that "knowledge" would gain power as an important means of production in the future, against important resources (land, capital, workforce) of the industrial society (Drucker, 1993). To find new sources of competitiveness, companies are turning to internal enterprise resources and organizational abilities established over time. Companies are seeking effective ways to manage such intangible assets, which can provide competitiveness for a core business (Hamel and Prahalad, 1989, 1990, 1994).

Florida, on the other hand, found that the rise of a new social class, a "Creative Class," has effected massive social changes over the past few decades (Florida, 2002, 2005). The Creative Class is a socioeconomic class which is a key driving force for the economic development of post-industrial society. Members of the Creative Class engage in work which creates meaningful new forms, and they derive much of their value from their role as purveyors of creativity. Since they have already had a huge economic impact, Florida observed that the business results of a company will determine how its workplace is organized for its Creative Class in the future. Thus, management of the people in this class will be one of the keys to competitiveness in the next era.

Regarding such opinions, the concept of "organizational learning" introduced by Senge provides us with a clue. Senge proposed to focus on employee training and the promotion of autonomous learning as a means to continuously improve organizational strength (Senge, 1990).

In addition, Nonaka expanded the concept of the organizational learning, and stated that knowledge created by individual employees is transformed into knowledge at an organizational level through communicationbased interactions among employees (Nonaka, 1991, 1995). He proposed the Socialization-Externalization-Combination-

Internalization (SECl) model, a knowledge creation framework in which organizational knowledge creates further levels of knowledge within an individual. The SECI model organized the idea of organizational learning into the concept of managing the "place" in which knowledge management happens.

Subsequently, the management of "place" develops into a management of social networks in the company. Davenport researched management methods for knowledge workers and found that competent knowledge workers glean most of their important information from their social networks (Davenport, 2005). In other words, they create relationships, both within and outside the workplace, through which they can gather advice, and play the role of information provider, thus allowing them to solve a range of work-related problems through the strength of their social networks. If companies can support these social networks from a management perspective, increased organizational strength will result.

The encouragement of these social networks is the focus of this paper, posing the issue of whether it is possible to foster collaborations in which employee communications of employees are developed through social networks. The authors analyzed this issue according to the following procedure:

(1) Extract a Creative Core in the case company.

(2) Make the collaboration network of the company by using an RFID system.

(3) Clarify relationships with the collaboration network and communication in the Creative Core.

(4) Examine the management method by considering common points of the case company and our previous research. 
Based on the analysis from (1) to (4), it is concluded that the collaboration network of a company is controlled by the Creative Core's communications toward dynamic management.

\section{Related works}

\section{Structural approach to social network}

Various previous researches examined the application of social networks among corporate organizations and the associated field of our research concept.

The origin is a study of the 'strength of weak ties' theory that Granovetter proposed (Granovetter, 1973, 1983, 1995). Granovetter examined the routes by which white-collar workers that changed jobs obtained important information with regard to their job change. The results showed that in most cases $(56.0 \%)$ acquaintances were the source of information, rather than classified advertisements in newspapers and the job placement office. Furthermore, it was recognized that the strength of weak ties, human relations where the contact frequency is routinely low, led to the success of a job change. These "weak ties" are interpreted by the social network theory as bridges between networks or local bridges between sub networks that carry the information we cannot usually know on the social networks of job hoppers. However, Friedkin and various researchers pointed out that Granovetter could not prove the functional advantage of the bridge, because his research had more weak ties than strong ties (Friedkin, 1980).

On the basis of this argument about weak ties, Burt proposed the concept of "structural holes". Burt looked at high-tech companies and investigated relationships between the social networks of upper-level managers and the speed of their promotions (Burt, 1992). Burt defined the "structural holes" as the loss of an immediate relation (disconnections between a company's partners). The more the relations with other employees are divided, the more the employee autonomy. Thus, the promotion of an employee to an executive job is accelerated by structural holes. While an employee's individual abilities and the various resources invested in that particular employee cannot be ignored, Burt also found that work performance is significantly influenced by the characteristics of the social network to which an employee belongs and by his or her position within the social network. In addition, Lin nominates (1) getting information from connected persons, (2) affecting persons through connected persons, (3) raising trust by a connected persons' behavior, and (4) using both resources in a strong tie, as reasons for the effects of the social network (Lin, 2001). Burt also suggested some action agendas for each employee, but they were not closely related to management.

One of problems was that Burt only gave suggestions for employees, not for management. In other words, the specific effects of a network structure on organizational performance remain unclear. Ahuja pointed out this point, and alternatively proposed that performance is generated by building dense, interconnected networks because social network linkages have some effects that are due to resource sharing and the access to knowledge as information conduits (Ahuja, 2000). Research relating to management by Cross et al. (Cross et al., 2004) clarified a systematic strategy mutually and intimately tying employees after they indicated some effects of a social network. Managing a social network in this way was the purpose of their research.

Further, Cross et al. classified the social networks of more than 60 companies across a range of industries into three categories (Cross et al., 2005). Depending on the type of social network, the differences were shown between the types of collaborative works generated through such networks. The optimal structure of social networks for business depends on the objectives of the network members. A compact and dense network is desirable for knowledge work like activities of the Creative Class. However, their proposal focused on activities such as sharing organizational purposes and holding social events to enable employees to 
The Power to Activate a Creative Core in Enterpris / Yuhashi \& lijima

mutually relate to each other. Their work was not based on the premise that management is actively aware of social networks.

\section{Types of Links in Social Networks}

Against the approach of a network structure such as the above, there is related research that deals with the types of links in social networks. Krackhardt et al. stated that we could recognize a perspective of the informal network by examining the three types of human relations of "advice," "trust" and "the communication" (Krackhardt et al., 1993). They also pointed out the necessity of management based on an informal network, and proposed the change of a formal organization adjusted to the actual situation of an informal network.

Along with Krackhardt et al., Ustuner analyzed the social network of the sales staff in the sales department (Ustuner et al, 2006). This is also a related research that deals with types of links in social networks. Excellent sales staff makes much more use of "Knowwho" compared to "Know-how" and they use four types of social networks depending on a progress of sales process from case analysis. The four types of social networks are same industry, inside cooperators, potential customers and existing customers. Furthermore, they proposed a sales force structure, compensation and skills development for systematically building a social network to the management of sales departments.

Such research dealing with the types of links have the objective that the effect of the information circulation in a social network supports certain actions of employees. Thus, management has to keep an eye on the types of links that have an accepted purpose (For example, they must keep an eye on links in collaborations if a purpose is to activate a knowledge work at a company).

\section{Management of Collaborative Place}

On the other hand, there is research which shows that creativity brings competitiveness. Florida, for example, argued for the growing role of creativity in the economy (Florida,
2002, 2005), and offered a characteristic definition of the socioeconomic class called the "Creative Class" as consisting of people who add economic value through their creativity. After the 1980's, the scale of Creative Class economic activities spread rapidly in comparison with the working class. The economic growth of the Creative Class was confirmed by Florida's quantitative analysis. Florida also compared the relative creativity in country and city environments, and discussed competitive strategy at the city level. He called particularly innovative people (for example in the fields of science, engineering, education, computer programming and research) the "SuperCreative Core"1. The Super-Creative Core's work entails problem finding along with problem solving. The economic activities of this class set precedents for judgments, such as lifestyle choices, for people throughout the world. Many companies will need to concentrate on management of creative work by the Creative Class going forward. Actually, Moody investigated three sociological collaboration networks (from 1963 to 1999) and found that a structurally cohesive core characterizes co-authorship networks (Moody, 2004). In addition, Florida describes a community or a power of place as a management approach. In business, the issue to manage the core community which the "Creative Class" forms comes out of such research.

A phenomenon that central persons lead a whole network is seen in a collaboration network.

Gloor used a case analysis of certain companies to show that social networks can lead to innovation, and he defined the type of social network that is ideal for enhancing business activities (Gloor, 2006). That network is called a Collaborative Innovation Network (COIN). Here, a COIN is a cyber team of self-motivated people with a collective vision, who collaborate through the World Wide Web to achieve a common goal by sharing ideas, information and work. Gloor considered examples of successful cases, including Daimler-Chrysler and IBM. 
Moreover, the Helsinki University of Technology and University of Cologne formed some virtual interdisciplinary teams collaborating on a common task. In these teams, innovations ripple from the innermost COIN core to the next larger collaborative network (Gloor, 2008) and these had core/periphery structures with a small-world network. Their core teams formed a highdensity network. Their periphery part is a network forming a ring around the core team, and had comparatively low density. Thus, it reported a co-relationship between a network core and performance.

Several management methods were explained (Gloor, 2006): the requirements for COIN, ways for employees to participate and formal changes of an organization for using COIN. There are three common steps in the COIN process that were outlined in their research. In the first step, a small core team learns about the idea of COIN. In the second step, the idea of COIN is shared in a larger team by increasing the number of members and their activities. In the third step, the team activates outside communications. For a manager to set up a social network in enterprise management, they should understand the current state of social networks. However, Gloor did not refer to this perspective.

The social network analyses in the above research were all based on a static aspect of looking at a company at a particular time. Even if researchers study the creation of a social network in an attempt to link a social network to a management method, they tend to miss the dynamic perspective of organizations because social networks change almost daily.

\section{Use of an RFID System}

Management has to grasp the situation in real time to realize dynamic management. Therefore we may use ICT (Information and Communication Technology). In this research, we used an RFID system as an approach to grasp the collaboration network of a company.
Generally, an RFID system is a technology used in a field of Supply Chain Management (SCM) in business. There is a lot of academic research in this field. For example, Quaadgras recognized an RFID network (in which multiple companies participated) as an ecosystem that is both cost-effective and convenient in his analysis of cases (Quaadgras, 2005). In addition, there is research of the " $\mathrm{B}$ to $\mathrm{C}$ " side (Wamba et al., 2008; Pramatari, 2007) and the "B to B" side (Wamba et al, 2006) in a field of SCM. Moreover, there is research for defense of a counterfeit market (Staake, 2005) and for fears of consumers about the privacy in business (Gunther et al., 2005; Spiekermann et al., 2005, 2006). However, we installed an RFID system on a human, not an object. Therefore we put such actions outside the scope of this research.

In comparison with the above, actions using RFID are not yet the mainstream in grasping human activity. For example, a junior skier offered a service that installed a GPS (Global Positioning System) transmitter to a person's foot at the ski resort "Whistler Blackcomb" at the Vancouver Olympics 2010. When parents are searching for a lost child, this service gives positional information of the lost child. And they are also able to confirm exercising results at home.

There is some research of such activities. Konkel created a collaborative game based upon wearable RFID technology called "Tagaboo" (Konkel, 2004). This game's goal is to find as many hidden RFID tags as possible on humans or objects. On the other hand, in the field of business, at events such as an international conference, all participants wear an RFID tag. And an RFID system supports matching when looking for a business partner (Counts, 2005). It proposed the possibility of collaborations from a business person's positional information and profile.

Then how does a company use an RFID system? McDonald studied a groupware in the case of a company, and explained that a "workplace's collaboration show that social 
relationships are a strong factor in determining who collaborates with whom" (McDonald, 2003). He proposed that management could guide users toward effective collaborations by using social networks. On the other hand, Eagle et al. made a social network using the IDs of wireless units (mobile phones) of employees at a company (Eagle et al., 2004). When an employee's mobile phone is turned on, a Bluetooth application that sends an ID "Bluetooth identifiers (BTID)" and a time stamp is automatically run. Workspace receivers gather the employees' positional information. It considered sharing of the same place to be a relation of communication that existed between employees. They made matches between a social network and profiles of employees and gave them an alert on the similarity among employees for causing collaboration. This is an innovative experiment, but this checked only the accuracy of having generated a social network with the Bluetooth ID of mobile telephones. As mentioned above, the use in the company of an RFID system has high potential, but it is limited to technical trial, most of the confirmation of the effects and the development of management methods have not been sufficiently performed.

\section{Method and Research Questions}

Luhmann presented a concept of the formation of social systems. He assumed that a communication activity is understood in a group and then human relationships and social regulations are created cognitively (Luhmann, 1973). Since no analysis method to confirm his ideas existed in the past, he thought that he could recognize a social system by making the border between a range of common social regulations and its external environment clear, without observing human relationships and social regulations by communication. But the technical evolution taking place in recent years in ICT made it possible to verify Luhmann's theory. In other words ICT has made it possible to grasp a social system from human relations formed by communications in a group.
The development of the recent ICT has two parallel movements: one is from fixed communication to ubiquitous communication, and the other is from personal ware to social ware. If we use ICT to grasp human movement by tracking with an RFID system or such, it is possible to consider an approach to managing organizational performance from a structural network perspective by understanding a situation in a business organization in which communication between employees leads to collaboration. Based on the related works mentioned above, we aimed to recognize dynamic collaboration activities by using an RFID system for the purpose of activating knowledge work, and devising a management method to form a high-density collaboration network.

\section{Collaboration Network}

McDonald, who used a social network for groupware, discovered that an employee's real social network did not match their individual perception (McDonald, 2003). Therefore, the recognition of a manager is also not accurate. It is necessary to grasp a correct social network to assume it is the grounds of the management method. Shetty et al. made a database of emails exchanged in the case of Enron Corp. and made a social network of employees, by setting email communication to an edge (Shetty et al., 2005).

However, to choose the employees that are important, they had to look for important information in emails by using text mining and natural language processing on an email exchange network. The email exchange may cause activities of important employees, but they are not the types of links which management wanted to directly grasp. Therefore it required difficult processing.

Moreover, the above-mentioned Eagle et al. made a social network based on sharing a same place using the BTID of mobile telephones (Eagle et al., 2004).

On this network, it added information on the similarity among the profiles of employees, and looked for points on which collaboration 
is possible. Based on the results to really activate collaboration, they proposed to rebuild a formal organization like a social network. As information in addition to sharing a same place, besides a profile, there is the characteristic of a place. McDonald explained that information sharing and the workplace environment were strong factors in collaborations. A workplace environment does not usually have a big change.

A meeting room is used for a meeting, and a break room is used for a break. It is considered that collaboration occurs from sojourn time to share the same place, in a peculiar ratio depending on the use of the place. Furthermore, collaborations may be changed by a state of information sharing every hour.

Therefore, we grasped the human relationships of employees from their sojourn time when they shared same places by using the RFID system in the company. We then added heaviness to their human relations at unique ratios of places in their office. This research considered these relations to be a collaboration network, and tried a formation of its network. Can this collaboration network be activated by emails exchanged among employees? It is a basic idea that we confirm this question and examine a management method.

\section{Creative Core and Management}

Our idea on an examination of a management method is as follow.

Florida defined the central persons in the Creative Class as the Super-Creative Core (Florida, 2002, 2005). The characteristic of this group is the ability to produce new forms or designs that are readily transferable and broadly useful. For example, scientists, engineers, university professors, poets, novelists, artists, entertainers, actors, designers, and architects are included in the Super-Creative Core. The employees in the case studies are not first-class scientists, but it seems that the central knowledge workers are very similar to the above definition of the Super-Creative Core. Moody and Gloor also recognized the existence of a core group in knowledge work (Moody, 2004; Gloor, 2008).

We therefore regarded these employees as a "Creative Core," defined as a group who creates the competitiveness in a core business. It does not have organizational control of tasks, does not handle support tasks, and creates substantial output through its own activities. For this group, we favored a management method of change to a work environment with collaboration through communication in place of a method of motivating or demanding efficiency.

In our previous research, we also discovered a "Creative Core." Unlike this paper, it analyzed a social network which changed dynamically in a case company (Yuhashi et al., 2008, 2009). It focused on the structural equivalence (meaning the node of the same role in a network) of a social network and extracted members of their proposal sales team. It found the relationship between communication and collaboration in the core group with the result that communication precedes collaboration.

Evans et al. explained a relationship between communication and collaboration in companies as follows: a social network of high density produces employees that trust each other, and reduces transaction costs of communication for their work. It enables many small communications. Therefore, as a result, it makes an organization in which it is easy to produce collaboration (Evans et al., 2005). They also suggested concrete means as a use of the collaboration tool, a visualization of results and an encouragement of team meetings. Assuming transaction costs of the communication on an individual link, an outbreak of the collaboration is strongly influenced by the quantity of communication of its link.

Therefore, our idea to examine a management method is something to activate a collaboration network via encouraging communications of the persons in a core.

\section{Definition and Approach}


We defined two important theoretical terms (Communication and Collaboration) to use for this research. "Communication" is defined as "the interactive processes employed by human beings in order to communicate their psychological content (including knowledge, emotions and will) between one another, using symbols such as body language, words, text, images, and so on, as mediational means." To date, many academic definitions have been applied to the concept of communication. Some people consider communication mechanically, that is, as "the process of convincing another through the repetition of stimulus and response," and others view it as "the process of transferring a meaning from one individual to another" (Okabe, 1993). This research is directed toward environments using information and communication technology devices, but at the same time, it requires a response to a range of situations within a workplace. Therefore we define communication as something not requiring a face-to-face encounter with another person; it is a process in which a medium (body language, words, text, images or other symbols) and communication content (knowledge, emotion, will or other psychological content) produce an action (a process of interaction between communicating parties). To be concrete, this paper regarded the number of emails as communication.

We defined "Collaboration" as "an activity that leads to an emergent result, which takes place alongside an act of communication within a group that has a mutually beneficial relationship." This "mutual benefit" is the process of sustaining and developing a society that is created by members with a feeling of fellowship and a sense of unity. These members act autonomously and collaboratively while taking care of each other's weaknesses. This "group" occurs when multiple parties begin to regulate and sustain their mutual actions and relationships, and they begin to share a certain amount of goodwill. When many elements and parties begin to influence one another, new attributes appear and are added; this is known as "emergence." In this definition, "Coordination" (e.g., the act of waiting in line, or any activity that involves autonomous acts in a way that does not require them to consider individual reactions) and "Cooperation" (e.g., a division of labor involved in a group translation, in which its members do not intervene with each other but merely bring along the individual results of their work) are not considered the same as collaboration. To be concrete, we regarded collaboration as the human relationships of employees made from their sojourn time when they shared same places by using an RFID system.

Finally, about the choice of the core member, the roles of employees in a business organization are identified in the case: the executive manager who controls the organization, the frontline managers, the staff who promote the core business, and the other staff who handle support tasks, etc. In these roles, the frontline managers and the staff who promote the core business are the sources of the organization's competitiveness. We can confirm whether core employees (chosen depending on an internal role) really function as a core.

Based on the above-mentioned considerations, the following are the research questions.

Research question 1: Various indexes
of a collaboration network are related to
communicative activities among
employees in a Creative Core.

Research question 2: Companies have the potential for managers to operate the Creative Core's collaboration network via the communicative activities of employees.

First, we consider the case of a large company and examine these hypotheses using multiple regression analysis. This research set communication data as explanatory variables and collaboration data as explained variables. Next, we examine the management method of the Creative Core with the results of the analysis. 


\section{Communication and Collaboration}

\section{The Company}

This analysis uses the case of a large company, the company. The company is a group company of a major mobile phone operator in Japan. The businesses of the company are development and maintenance operations of corporate information systems, and sales of hardware relating to information systems. The paid-in capital is 652.6 million JPY, and sales totaled 34.1 billion JPY (as of the fiscal year ending March 2009). The number of employees is 696 (as of March 31, 2009). This research covered its system integration division, which plans, develops and operates various mobile solutions, and also builds information systems to fit various customer needs. The employees of the division devise various customizations drawing on their own knowledge. The system integration industry is an extremely competitive market. Therefore, to name one characteristic, every employee is required to use mobile phones in their system integration for competitiveness.

The company has a characteristic method of organizational administration. In system integration companies, the account managers and the system developers generally belong to separate divisions, but in the company, the account managers and system developers belong to the same division. Two advantages of this characteristic are as follows. One is that it is easy to adapt customer needs to systems. The other is a speedup of work by decreasing some of the processes between associated sections in an organization. There are many kinds of mobile solutions, and suitable project members are assigned to meet every customer need. For system integrations, communication with various members is necessary for every project. Because customer needs are different in every project, it is demanded that employees with various skills engage in collaboration. Moreover, collaboration involving various skills requires organizational communication among employees.

\section{Creative Core}

The system integration division of the company includes an executive manager, some senior managers, frontline managers, chief engineers, many programmers, some sales managers and some support staff. Usually, frontline managers and chief engineers become project leaders of system integration. Programmers join a project as needed. Thus, the lineup of members is different in every project, and the division has many parallel projects to promote.

Above all, the project achieves large gains in competitiveness through the knowledge work of the frontline managers and chief engineers, who create the main part of the system solutions. Therefore, we chose three frontline managers and two chief engineers as the Creative Core. We clarified the relations between the communication activity of these employees (Creative Core members) and their sub collaboration networks that set them in its center, using multiple regression analysis, as follows.

\section{Communication}

Our analysis included 31 employees belonging to the mobile solution group of the system integration division. In the system integration division, employees use desktop computers at their own desks. Furthermore, mobile phones were not heavily used because many of the employees were inside the office. Most communication other than direct conversation was conducted by the use of indirect media, such as the exchange of email. Therefore, the exchange of email represented most of the communication that took place using indirect media. The average number of emails per week received by one employee from other employees in the same division was 22.08 , and the average number of emails sent was 25.91 .

\section{Collaboration}

We handled the collaboration as follows. There are many inside employees in the system integration division during the day. The collaboration of this division occurs in the office. The office has a large work room with 
The Power to Activate a Creative Core in Enterpris / Yuhashi \& lijima

individual desks for each employee, several meeting rooms and two break rooms. It is thought that communication occurs among employees because these areas are shared, and then collaboration occurs from this communication in a specific ratio, depending on the use of each place.

Therefore, this division's collaboration network can be visualized by an RFID system (Figure 1). The employees for this analysis wore an RFID tag, which indicated their position in the office - a unique ID number was assigned to the RFID tag, and the tag sent a signal with the ID number every 30 seconds through an electronic wave. We installed 17 antennas in the office to receive these signals and detect employees' positions in the office. In this way, the RFID system recognized employees positioned in the same place.

In addition, another signal was sent when an employee pushed the button on the tag. The rule for using this button was as follows: when collaboration was created by communication between employees, they pushed the button. We added up the number of times that buttons were pushed at every antenna. Next, we measured the time when employees stayed in the perception area (a diameter of around $5 \mathrm{~m}$ ) of the same receiver. It considered that employees performed some kind of interaction if they stayed in a perception area of the same receiver.

On the other hand, uses are different at each place even if they shared the same place.
However, if an employee belongs to the same organization, it is assumed that they use each place in the same way. We standardized the numbers of each antenna with the total number of times that a button was pushed, and considered these numbers to be the induction ratios to generate collaboration peculiar to a place. It performed a heaviness charge account by multiplication sojourn time and induction ratios of each place. We decided this heaviness charge accounted for the virtual outbreak value of collaborations. Thus, the collaboration between employees was confirmed by determining the sojourn time of every place and the outbreak frequency of the collaboration.

The collaboration network of the company (from November 23, 2008 to March 28, 2009) made through these means is shown in Figure 2. In Figure 2, each node denotes an individual employee and an edge linking two nodes indicates collaboration between those two employees.

\section{Procedure}

We divided the data acquisition of the company into two stages.

The first stage of data acquisition was gathering the facts. For the first stage, we collected data from November 23, 2008 to December 20, 2008 (4 weeks). To investigate research question 1 , the communication and state of the collaboration network were monitored from November 23, 2008 to December 20, 2008.

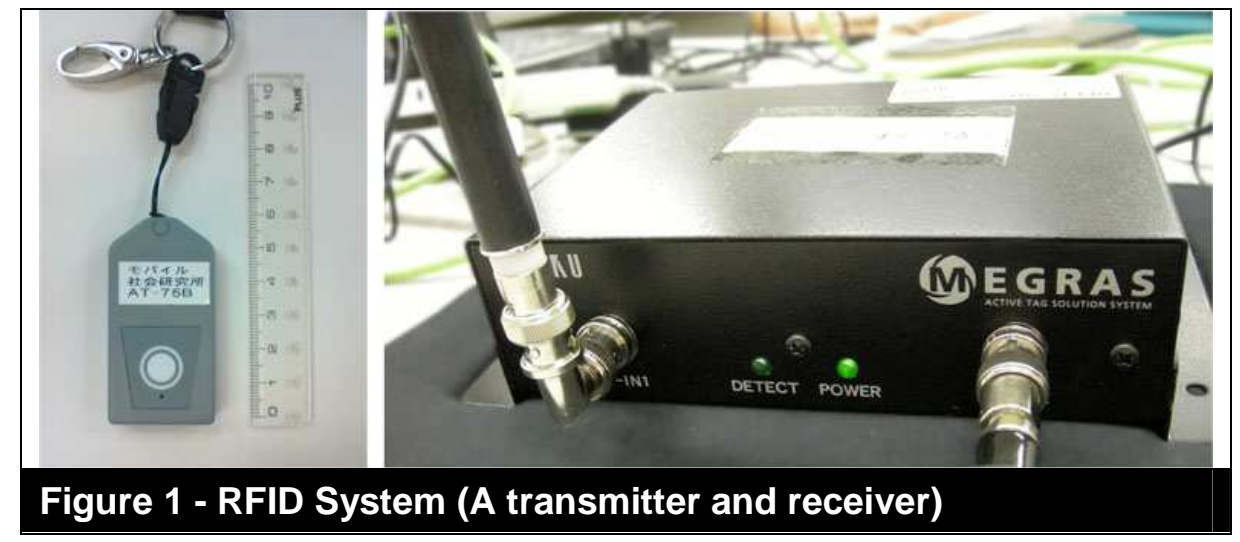


The second stage was an experiment to practice management methods. For the second stage, we collected data from March 8, 2009 to March 28, 2009 (3 weeks). To investigate research question 2, we conducted an experiment that changed the state of the collaboration network by intentionally increasing the volume of Creative Core communications.

Measures to increase the communication of Creative Core members were taken from March 8, 2009 to March 28, 2009. The experiment confirmed the effect of those measures on the state of communication and collaboration.

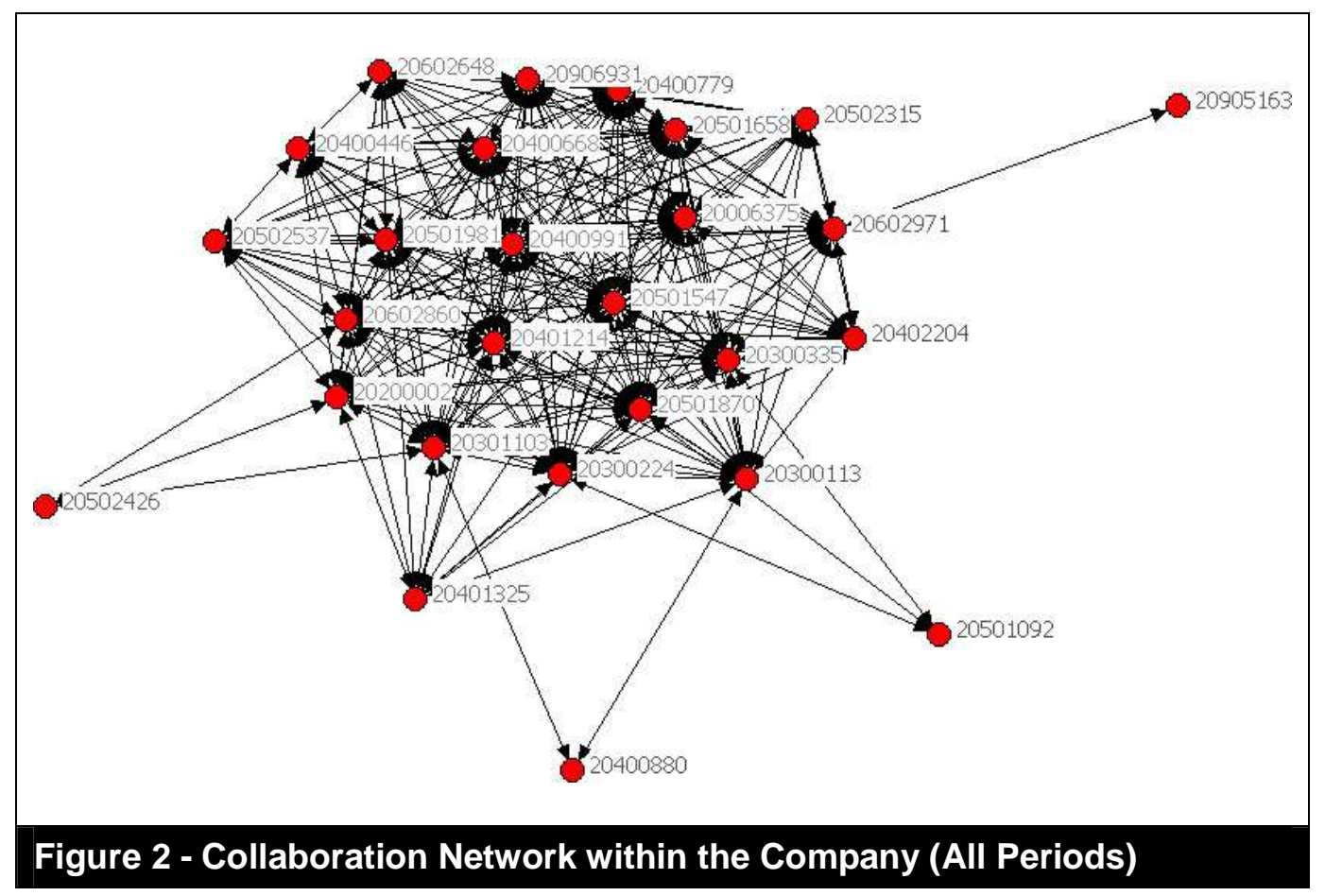

\section{Analysis of Relation between Communication and Collaboration}

We used multiple regression analysis to elucidate the relation between communication and collaboration in the company. We considered whether an employee of the Creative Core can show performance in a company. Therefore it extracted the sub network that set the employee of the Creative Core in its center from the collaboration network of the whole organization, and confirmed its state.

The fact that employees have a large social network means that they have many more resources available. We considered the "Size of an egocentric network" as an explained variable. In addition, to examine whether an employee is in an advantageous position within the egocentric network, we also considered the "Degree of an egocentric network," which is one of the indicators of an employee's centrality as another explained variable. Furthermore, to measure whether employees achieve the part of mediation between other neighboring employees in a social network, we considered the "Betweenness of an egocentric network" as an explained variable. It indicates whether an employee serves as a mediator between other employees.

\section{Explanatory Variables}

Indirect communications that are change factors of the collaboration networks are the 
sending and receiving of emails. And the sending and receiving of emails are independent. As data concerning indirect communication activities, the following two categories from their email system use log were taken as explanatory variables.

\section{[Explanatory variables]}

- The number of emails sent per week

- The number of emails received per week

\section{Explained Variables}

From a collaboration network that was visualized using an RFID system, the indexes that show the features of the egocentric network of Creative Core members were set as the explained variables: "Size of an egocentric network," "Degree of an egocentric network" and "Betweenness of an egocentric network."

\section{[Explained variables]}

- Size of an egocentric network (an employee with a social network has many more collaboration resources available)

- Degree of an egocentric network (an employee is in an advantageous position within his or her egocentric network)

- Betweenness of an egocentric network (an employee serves as a mediator between other employees)

\section{Tools of Analysis}

Three states of Creative Core egocentric networks had changed or confirmed the correlation with the email sending and receiving, based on an argument that communication forms collaboration. But the number of data which we gained from the experiment in all seven weeks is not large enough (4 weeks and 5 persons). Therefore we assumed a multiple regression analysis of the least-squares method foreknowledge. And performed a multiple regression analysis based on Markov chain Monte Carlo methods (MCMC) of Bayesian statistics. We thus found the confidence interval of the explanatory variables.

\section{Results of Analysis}

We carried out a multiple regression analysis using the data of the monitoring period (from November 23, 2008 to December 20, 2008) for each of the explained variables. This explains the correlation results of each explanation variable as follows. The foreknowledge is a street of Table. 1.

The estimated equation using two explanatory variables showed $R^{2}$ : 0.4 in Size and was correlative. Similarly the estimated equation of the Degree showed $R^{2}: 0.41$, and there was correlation. However, some estimated equations of Betweenness had weak $R^{2}: 0.38$.

\begin{tabular}{|l|c|c|c|}
\hline \multicolumn{4}{|c|}{ Table 1-Results of Multiple Regression Analysis (first half period) } \\
\hline & Netw ork sie & Degree centrality & Betweenness centrality \\
\hline Coefficient & 0.68 & 0.69 & 0.67 \\
Ad jisted R2 & 0.40 & 0.41 & 0.38 \\
\hline
\end{tabular}

\section{Network Size}

The results of the analysis of the egocentric network size showed the high multiple correlation coefficients $R$ of 0.68 and $R^{2}$ of 0.40 when adjusted for degrees of freedom (Table 1). We confirmed the confidence interval of the explanatory variable to use the Bayesian statistics of the Markov chain Monte Carlo (MCMC) methods with foreknowledge of this estimated equation.
Regarding the Size of Creative Core egocentric networks, the distribution was as follows: the mean coefficient of the number of emails sent was 0.152 and the confidence interval of $95.0 \%$ is from 0.040 to 0.265 (Figure 3). The mean coefficient of the number of emails received is 0.061 but the confidence interval of $95.0 \%$ was from - 0.228 to 0.353 (Figure 4). The explanatory variable of the number of emails received is not 
meaningful, because it includes 0 in confidence interval. From the above, if the number of emails sent increases, the Creative Core egocentric collaborative network grows bigger.

\section{Centrality}

-Degree of Centrality
The results of the analysis of the degree of egocentric networks showed extremely high multiple correlation coefficients $R$ of 0.69 and $R^{2}$ of 0.41 when adjusted for degrees of freedom (Table 1). We confirmed the confidence interval of the explanatory variable to use the Bayesian statistics of the MCMC methods with foreknowledge of this estimated equation.

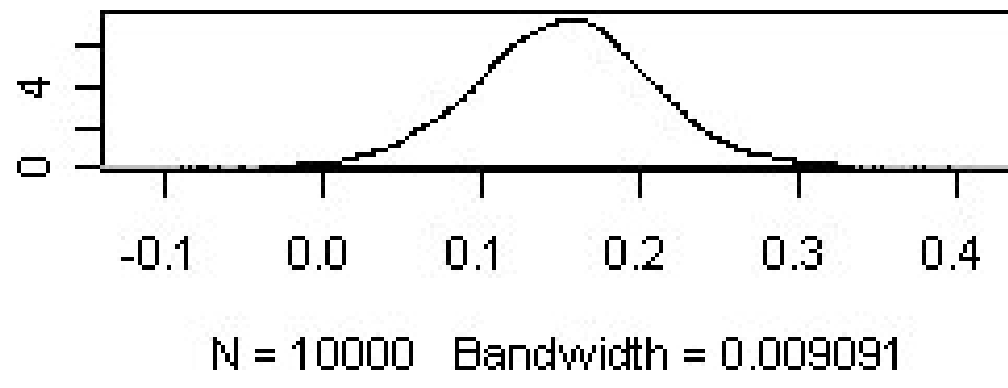

Figure 3 - Density of the Number of Emails Sent (Network Size)

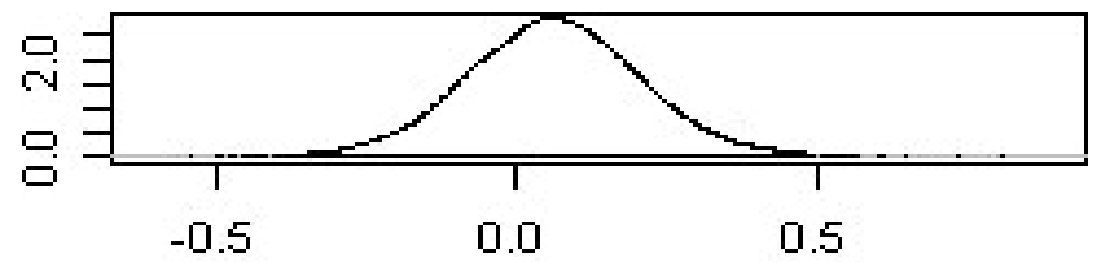

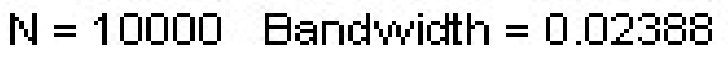

Figure 4 - Density of the Number of Emails Received (Network Size)

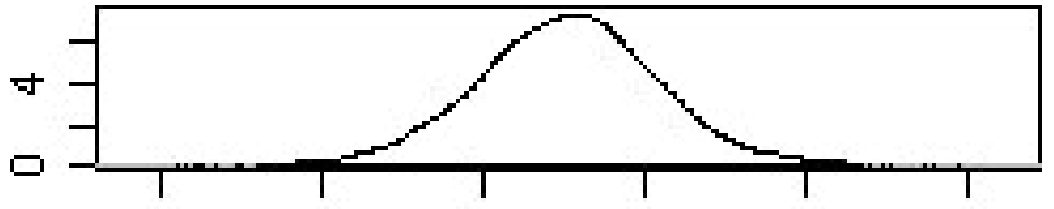

$\begin{array}{llllll}-0.1 & 0.0 & 0.1 & 0.2 & 0.3 & 0.4\end{array}$

N = 10000 Bandwiotth = 0.0010091

Figure 5 - Density of the Number of Emails Sent (Degree) 
The Power to Activate a Creative Core in Enterpris / Yuhashi \& lijima

Regarding the Degree of Creative Core egocentric networks, the distribution was as follows: the mean coefficient of the number of emails sent was 2.529 and the confidence interval of $95.0 \%$ is from 0.656 to 4.398 (Figure 5). The mean coefficient of the number of emails received is 1.359 but the confidence interval of $95.0 \%$ was from -3.443 to 6.216 (Figure 6). The explanatory variable of the number of emails received is not meaningful, because it includes 0 in confidence interval. From the above, if the number of emails sent increases, the Creative Core relations increase on the collaborative network.

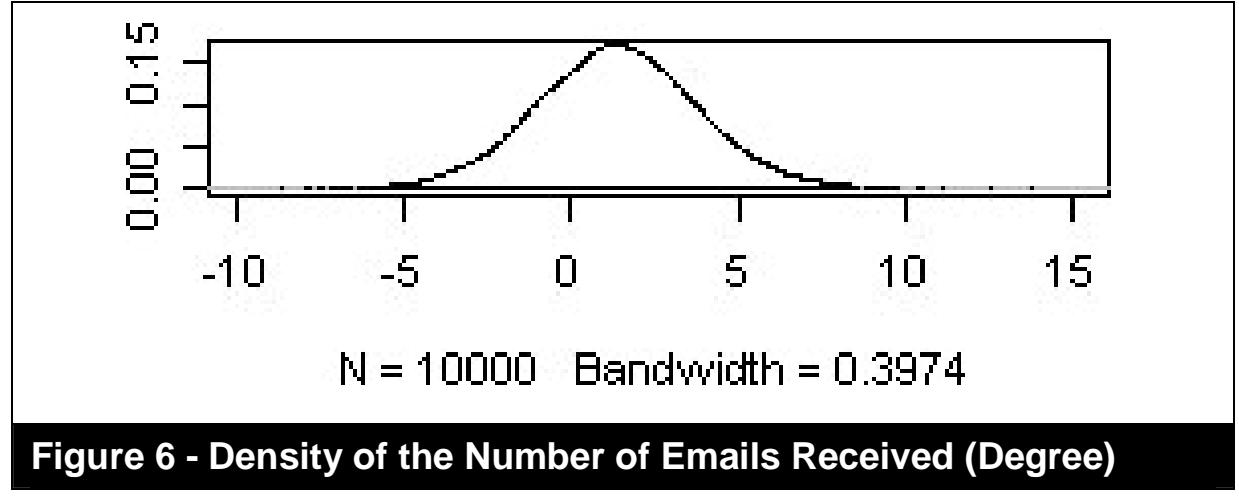

\section{- Betweenness of Centrality}

The analysis of betweenness showed slightly weak results with the multiple correlation coefficients $R$ of 0.67 and $R^{2}$ of 0.38 after adjustment for degrees of freedom (Table 1 ).
We confirmed the confidence interval of the explanatory variable to use the Bayesian statistics of the MCMC methods with foreknowledge of this estimated equation.
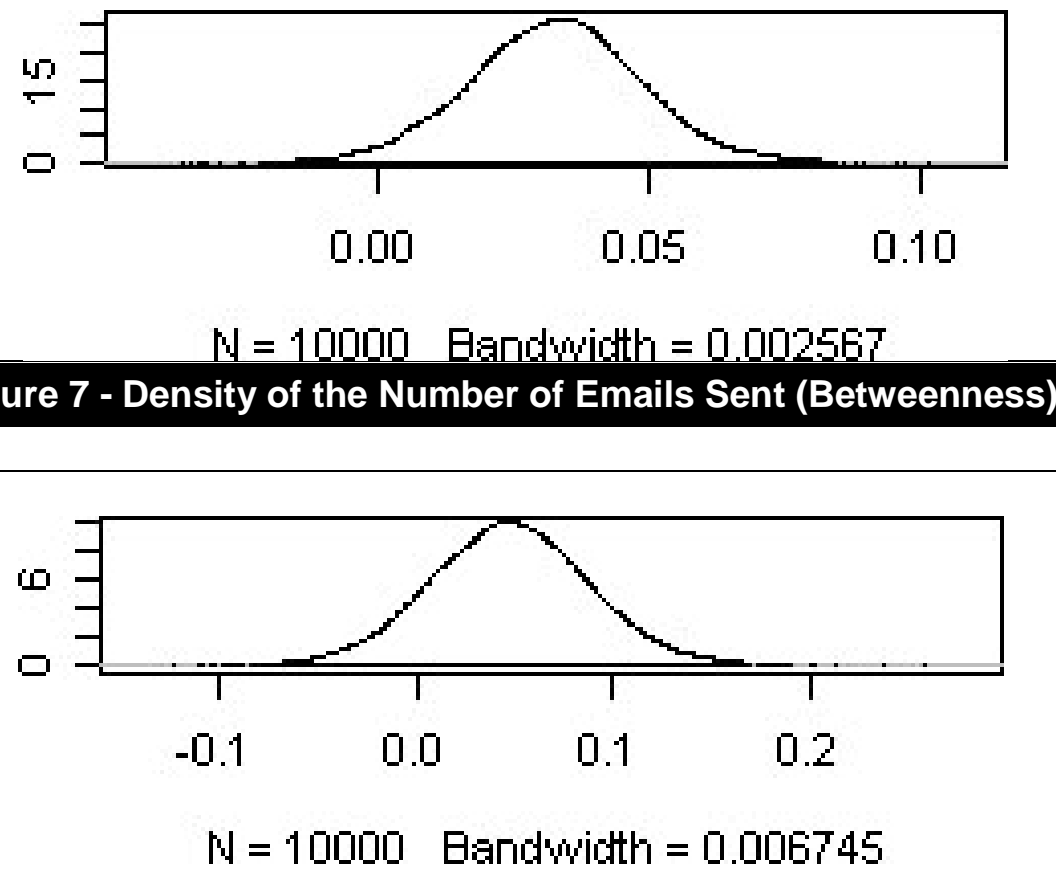

Figure 8: Density of the Number of Emails Received (Betweenness) 
Regarding the Betweenness of Creative Core egocentric networks, the distribution was as follows: the mean coefficient of the number of emails sent was 0.033 and the confidence interval of $95.0 \%$ is from 0.001 to 0.065 (Figure 7). The mean coefficient of the number of emails received is 0.048 but the confidence interval of $95.0 \%$ was from -0.034 to 0.130 (Figure 8). The explanatory variable of the number of emails received is not meaningful, because it includes 0 in confidence interval.

\section{Discussion about Relations}

Even though the correlation for betweenness is somewhat weak, the overall results of estimating and testing each regression coefficient supported that a relationship exists between the act of communication and the status of collaboration networks.

This indicates that the size and degree of egocentric networks fluctuate immediately when communication is changed in response to an instruction from management. However, betweenness does not link communication activities. Betweenness is a function of the number of employees on the shortest path between two employees. Because betweenness is made by the number of shortest passes, even if the Creative Core member network size increases, the betweenness does not decrease.

If collaboration is activated by his or her communication with an employee who is a Creative Core member, the degree of that member increases. The reason why betweenness does not decrease with the increase of degree is that the employees do not activate collaboration between employees other than themselves. In other words, the Creative Core member links communicative activities and changes the status within their collaboration network, but it is thought that the influence on other members or on a whole division is small.

The relation between communication and collaboration was verified by the above results.

\section{Experiment of Management}

Next, we conducted an experiment in which we changed the state of the Creative Core members in the collaboration networks by intentionally increasing the volume of communications from March 8, 2009 to March 28, 2009. The means of increasing communication were mailing list discussions about the idea of a new mobile solution and the increasing of information sharing from the executive manager. In addition, Table 2 confirms the significance of the degree of collaboration network. However, the betweenness did not relate enough to communicative activities.

The number of emails sent by Creative Core members increased as a result of these measures, as shown in Figure 9. However, Figure 9 also shows that the number of emails sent decreased in the week of March 15. This is a strong seasonal factor due to a shortening of work hours for negotiations between management and labor.

The results of multiple regression analyses of the egocentric network size showed high multiple correlation coefficients $\mathrm{R}$ of 0.67 and R2 of 0.40 when adjusted for degrees of freedom in all periods (the first stage and the second stage), in Table 2.

We confirmed the confidence interval of the explanatory variable to use the Bayesian statistics of the MCMC methods with foreknowledge of this estimated equation. Regarding the Size of Creative Core egocentric networks, the distribution was as follows: the mean coefficient of the number of emails sent was 0.124 and the confidence interval of $95.0 \%$ is from 0.036 to 0.212 (Figure 10). The mean coefficient of the number of emails received is 0.112 but the confidence interval of $95.0 \%$ was from -0.104 to 0.327 . The explanatory variable of the number of emails sent was the about the same confidence interval as the first half experiment. 


\section{Table 2 - Results of Multiple Regression Analysis (All Periods)}

\begin{tabular}{|l|c|c|c|} 
& Netw ork size & Degree centrality & Betweenness centrality \\
\hline Coefficient & 0.67 & 0.71 & 0.63 \\
Ad jisted R2 & 0.40 & 0.46 & 0.35 \\
\hline
\end{tabular}
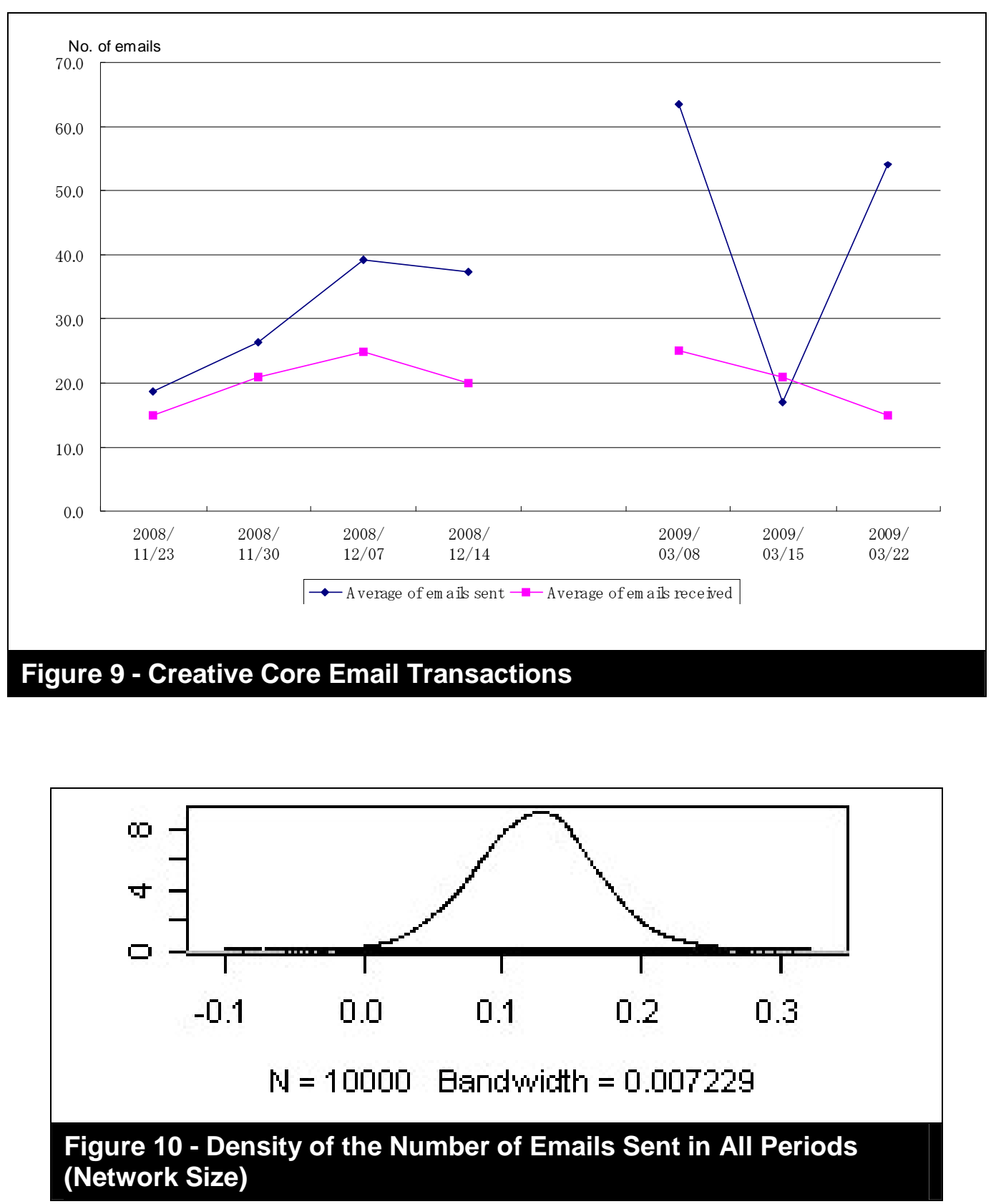

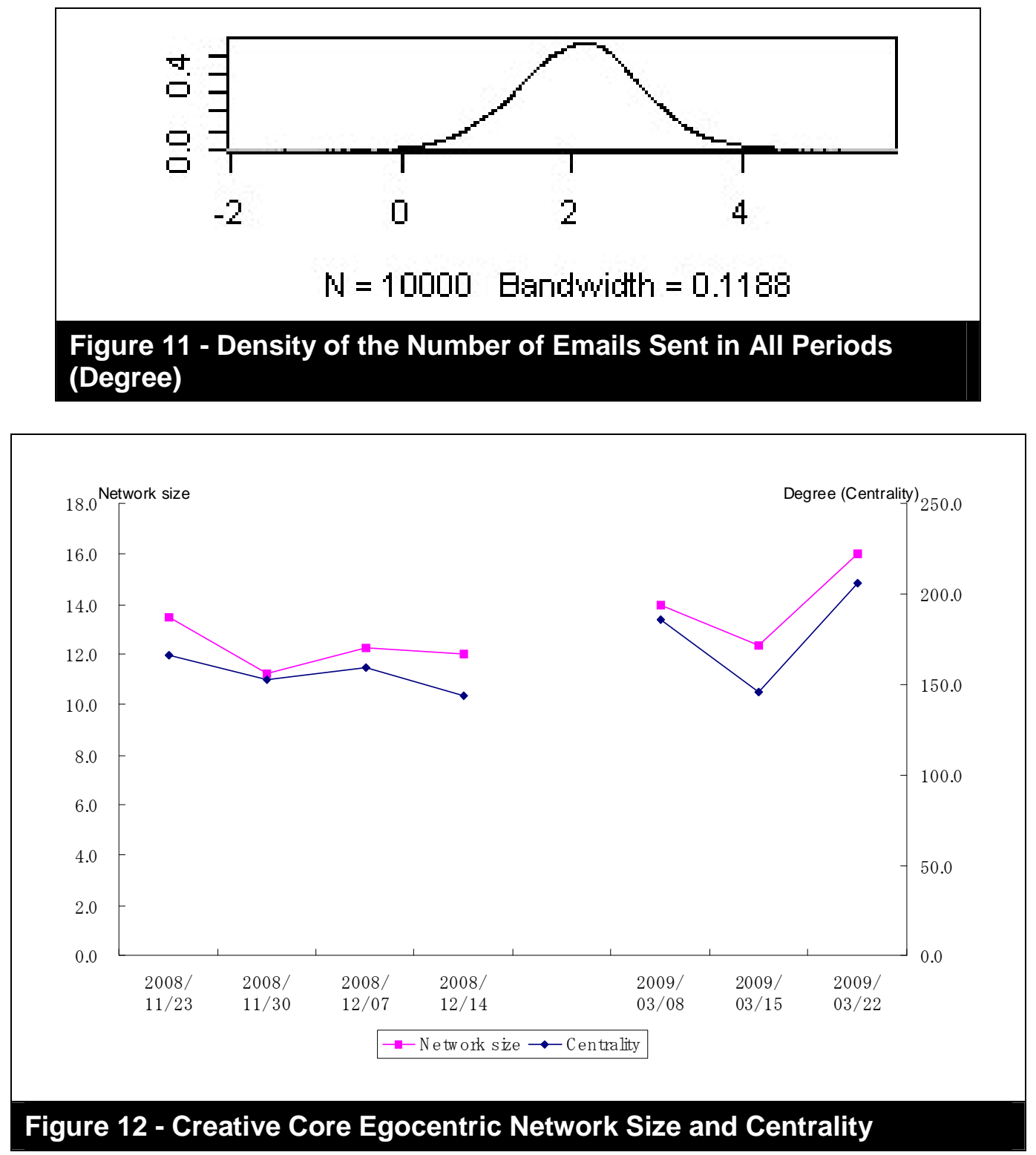

Regarding the Degree of Creative Core egocentric networks, the distribution also was as follows: the mean coefficient of the number of emails sent was 2.091 and the confidence interval of $95.0 \%$ is from 0.656 to 3.549 (Figure 11). The mean coefficient of the number of emails received is 2.509 but the confidence interval of $95.0 \%$ was from -1.028 to 6.045 . The explanatory variable of the number of emails sent was the about the same confidence interval as the first half experiment, as well.
It was shown that the Size and the Degree were linked to the emails sent of Figure 9, and increased and decreased in Figure 12.

\section{Conclusion}

Invested enterprise resources and the innate abilities of employees are not the only factors that contribute to the performance of a company. One added factor is activation of collaboration produced by the communication of the workplace. Milward mentioned that power in networks accrues to persons who are at the center of a web of collaborative 
The Power to Activate a Creative Core in Enterpris / Yuhashi \& lijima

activity. And they control the flow of various resources (Milward et al., 2006).

We showed the collaboration network of the company by using an RFID system. It was able to better show the state of the egocentric collaboration networks of a creative core (that produces competitiveness), via the communication among employees. If collaboration spreads in a company that has to strategically utilize knowledge creation to respond to the market, the management of situations in which collaboration arises in relation to its communication may lead to competitive advantages.

\section{Suggestions for Management}

Milward thought that an effective network management development of coordinating structures was necessary. It is not the same as conventional management. In this research also, the management method of an interpersonal relationship network in business with reference to knowledge work was examined with the goal of strengthening competitiveness.

The system integration division of the company was analyzed as to whether it was possible to foster collaborations in which communication of employees is developed through social networks. The communication activities and the status of the Creative Core egocentric collaboration networks confirmed a strong correlation. Our finding is that the position changes on a collaboration network for the Creative Core members through managerial instructions on communicative activities. In other words, it is easy to achieve a lot of collaborative work if managers can adequately distribute information to these members. Management has the task to facilitate that employees participate in a collaboration network. It differentially allocates various resources based on their role in a collaboration network of a company. In the past, each employee was a unit of execution in a business understood by the management. In management concentrating on the Creative Core, the operation potential for knowledge work increased. It may be a paradigm shift of the management method that is changing from each individual employee to the group.

On the other hand, RFID systems are used in distribution management or inventory control in many cases. Companies which are aware of the actual situation of collaboration, using an RFID system to activate the organization, have a significant advantage. We think that this point is one of the vital reasons to implement an RFID system in business. As described above, we discovered the potential of managing collaboration networks, and the new application of an RFID system. Moreover, Eagle et al. pointed out that it is possible to realize social solutions by using Bluetooth ID of mobile phones as a beacon specifying a user (Eagle et al., 2004). Since RFID is similar technology, this field can develop as a social ware binding a company's collaboration and employees' communication activities in the future.

\section{Discussion and Future Work}

Our research yielded the same results in a division of a large company (the subject company) following our previous research involving a small company. We may be able to make use of this knowledge in companies that are different in scale and type of industry. However, only elucidation of the mechanism of collaboration produced via communication can enable theoretical generalization. In this research, we don't yet have this.

Moreover, the communicative activities of key persons among the employees and the relations with a collaboration network were not covered in this research.

It is assumed that the key people in the distribution of information may influence the whole organization. Future research is required to analyze this point through additional analyses, and to attempt generalization by increasing case studies.

Finally, our research includes some privacy concerns. Perhaps management will be seized with the impulse that they want to give an individual employee an order or advice, when they grasp a social network. However, this is an unpleasant thing for most 
employees. It is necessary to limit the people who can view a social network without employees of their fellow worker. When a company uses an RFID system to confirm the location of employees, the employees are likely to feel at a disadvantage (a breach of privacy) with management. Since management cannot present advantages which exceed this disadvantage for employees, problems may occur. Companies which are aware of the actual situation of collaborations, using an RFID system to activate the organization, have a significant advantage. In this research, we considered the following: only general managers could view the social networks and do not give orders to an individual employee. However, this is a future issue.

\section{References}

Ahuja, G. (2000). "Collaboration Networks, Structural Holes, and Innovation: A Longitudinal Study," Administrative Science Quarterly, 45(3), 425-455.

Burt, R. S. (1992). STRUCTURAL HOLES: The Social Structure of Competition, Harvard University Press.

Counts, S., John Geraci, J. (2005). Incorporating Physical Co-presence at Events into Digital Social Networking, Late Breaking Results: Posters, CHI 2005, April 2-7, Portland, Oregon, USA.

Cross, R. and Parker, A. (2004). The Hidden Power of Social Networks: Understanding How Work Really Gets Done in Organizations, Harvard Business School Press.

Cross, R., Liedtka, J. and Weiss, L. (2005). A Practical Guide to Social Networks, Harvard Business Review, 83, pp. 124-132.

Davenport, T. H. (2005). Thinking for Living: How to Get Better Performance and Results for Knowledge Workers, Harvard Business School Press.

\section{Acknowledgments}

The authors thank General Manager Hirofumi KOJIMA and employees of the System Integration Division, DOCOMO Systems, Inc. for cooperating with our experiment for this research. We also thank Dr. Koichi YANO of the Economic and Social Research Institute, Cabinet Office, Japanese Government for advice on Bayesian statistical analysis, and Mr. Hiroki GOTOU of Mobile Society Research Institute, NTT DOCOMO, INC. for assistance with data collection.

\footnotetext{
Florida called classic knowledge-based workers "Creative Professionals" in contrast to the newly defined "Super-Creative Core" (Florida, 2002). They have the knowledge to solve specific problems (for example in healthcare, business, finance, the legal sector, and education) through higher degrees of education.
}

Drucker, P. F. (1993). Post-Capitalist Society. Harper Collins Publishers, Inc.

Eagle, N., Pentland, A. (2004). Social Serendipity: Proximity Sensing and Cueing, MIT Media Laboratory Technical Note 580, May.

Eagle, N. N. (2005). Machine Perception and Learning of Complex Social Systems, Massachusetts Institute of Technology.

Evans, P., Wolf, B. (2005). Collaboration Rules. Harvard Business Review, July-August.

Friedkin, N. (1980). A test of the structural features of Granovetter's 'strength of weak ties' theory. Social Networks, 2, 411-422.

Florida, R. (2002). The Rise of the Creative Class: And How It's Transforming Work, Leisure, Community and Everyday Life, Basic Books, Inc.

Florida, R. (2005). The Flight of the Creative Class: The New Global Competition 
The Power to Activate a Creative Core in Enterpris / Yuhashi \& lijima

for Talent, HarperCollins Publishers, Inc.

Gloor, P. A. (2006). SWARM CREATIVITY: Competitive Advantage through Collaborative Innovation Networks, Oxford University Press.

Gloor, P. A., Paasivaara, M., Schoder, D., Willems, P. (2008). "Finding Collaborative Innovation Networks through Correlating Performance with Social Network Structure", International Journal of Production Research, 46(5).

Granovetter, M. (1973). "The strength of weak ties". American Journal of Sociology, 78(6), pp. 1360-1380.

Granovetter, M. (1983). The strength of weak ties: A network theory revisited. Sociological Theory, 1, pp.201-233.

Granovetter, M. (1995). Getting a job: A study of contacts and careers, $2^{\text {nd }} e d$. Chicago: University of Chicago Press.

Günther, O., Spiekermann, S. (2005). RFID and the Perception of Control: the Consumer's View, COMMUNICATIONS OF THE ACM, September, Vol. 48, No. 9.

Hamel, G. and Prahalad, C. K. (1989). Strategic Intent. Harvard Business Review, May-Jun, pp. 63-76.

Hamel, G. and Prahalad, C. K. (1990). The Core Competence of the Corporation. Harvard Business Review, May-Jun, pp. 79-91.

Hamel, G. and Prahalad, C. K. (1994). Competing for the Future. Harvard Business School Press.

Hossain, L., Fazio, D. (2009). "The social networks of collaborative process", Journal of High Technology Management Research, Vol. 20, pp. 119-130.

Konkel, M., Leung, V., Ullmer, B., Hu, C. (2004). Tagaboo: a collaborative children's game based upon wearable RFID technology, Pers Ubiquit Comput, No. 8, pp. 382-384.

Krackhardt, D., Hanson, J. R. (1993). Informal networks: the company behind the chart. Harvard Business Review, October-November.

Lin, N. (1982). Social resources and instrumental action. (In) P. V. Marsden, \& N. Lin(Eds.) Social structure and network analysis. Sage, pp.131-145.

Luhmann, N. (1973). Vertrauen: Ein Mechanismus der Reduktion sozialer Komplexitat, Stuttgart.

McDonald, D. W. (2003). Recommending collaboration with social networks: a comparative evaluation, Proceedings of the SIGCHI conference on Human factors in computing systems, Ft. Lauderdale, Florida, USA, pp. 593600.

Milward, H. B., Provan, K. G. (2006). A Manager's Guide to Choosing and Using Collaborative Networks, IBM Center for The Business of Government.

Moody, J. (2004). "The Structure of a Social Science Collaboration Network: Disciplinary Cohesion from 1963 to 1999", American Sociological Review, 69(2), pp. 213-238.

Newman, M. E. J. (2001). Scientific collaboration networks. I. Network construction and fundamental results, Physical Review E, Vol. 64, 016131.

Nonaka, I. (1991). The Knowledge-Creating Company. Harvard Business Review, Nov-Dec, pp. 96-104.

Nonaka, I. and Takeuchi, H. (1995). The Knowledge Creating Company. Oxford University Press.

Ohira, M., Ohsugi, N., Ohoka, T., Matsumoto, K. (2005). Accelerating Cross Project Knowledge Collaboration Using Collaborative Filtering and Social Networks, 
ICSE '05, May 15-21, St. Louis, Missouri, USA.

Okabe, R. (1987). Basic concept of communication, Cross-cultural communication. Yuhikaku Publishing Co., Ltd., pp. 15-38.

Pramatari, K. (2007). "Collaborative supply chain practices and evolving technological approaches", Supply Chain Management: An International Journal , 12(3), pp. 210-220.

Quaadgras, A. (2005). Who joins the Platform? The Case of the RFID Business Ecosystem, Proceedings of the 38th Hawaii International Conference on System Sciences.

Senge, P. M. (1990). The Fifth Discipline. Doubleday.

Shetty, J., Adibi, J. (2005). Discovering Important Nodes through Graph Entropy the Case of Enron Email Database, International Conference on Knowledge Discovery and Data Mining, Proceedings of the 3rd international workshop on Link discovery, Chicago, Illinois, pp. 74-81.

Spiekermann, S., Ziekow, H. (2005). RFID: A 7 Point Plan to Ensure Privacy, European Conference on Information Systems (ECIS) 2005 Proceedings.

Spiekermann, S., Ziekow, H. (2006). "RFID: A Systematio Analysis of Privacy Threats \& A 7-Point Plan to Adress Them", Journal of Information Systems Security, 1(3).
Staake, T., Thiesse, F., Fleisch, E. (2005). Extending the EPC Network: The Potential of RFID in AntiCounterfeiting, Symposium on Applied Computing Proceedings of the 2005 ACM symposium on Applied computing, Santa Fe, New Mexico, SESSION: Ubiquitous computing (UC), pp. 1607-1612.

Ustuner, T., Godes, D. (2006). Better Sales Networks. Harvard Business Review, July-August.

Wamba, S. F., Lefebvre, L. A., Lefebvre, E. (2006). Enabling Intelligent B-to-B eCommerce Supply Chain Management Using RFID and the EPC Network: A Case Study in the Retail Industry, ICEC'06, August 1416, Fredericton, Canada.

Wamba, S. F., Boeck, H. (2008). "Enhancing Information Flow in a Retail Supply Chain Using RFID and the EPC Network: A Proof-ofConcept Approach", Journal of Theoretical and Applied Electronic Commerce Research (Electronic Version), 3(1), pp. 92-105.

Yuhashi, H., lijima, J. (2009). How Can We Manipulate a Communication Network to Create Collaboration?, AMCIS 2009 Proceedings, Paper. 97., San Francisco, August.

Yuhashi, H. and lijima, J. (2008). How Can We Manage Collaboration Network via Communication? Proceedings of the 12th PACIS, pp. 347-358. 
The Power to Activate a Creative Core in Enterpris / Yuhashi \& lijima

\section{About the Authors}

Hiroyasu Yuhashi is a Senior Researcher and a Manager of the Mobile Society Research Institute, NTT DOCOMO, INC. And he is a Ph.D Candidate of the Graduate School of Decision Science and Technology, Tokyo Institute of Technology, JAPAN. His major interests are Communication \& Collaboration, M-Business, and Noncontact e-money. lijima Junichi is the Chair, a professor of the Department of Industrial Management and Engineering, Tokyo Institute of Technology, JAPAN. His major interests are BPM, Systems Integration, M-Business, IT Value and Systems Theory. He is the author and coauthor of many papers, articles and books in Japanese and international journals as well. 